\section{Resident-On-Call Service}

The residency program at the London Health Sciences Centre has been in existence for several years. While this program is first and foremost an educational opportunity intended to develop the competence of future practitioners, the residents participate in the provision of regular education programs and provide clinical services. The provision of clinical services usually occurs during the residents' experiential rotations, and this contribution of residents has been documented in the past. ${ }^{1}$ Because of inadequate staffing, some services may not be covered, and the shortfall at the Victoria site is 5.0 full-time equivalents (FTE). Routine screening of orders continues to be performed, but if the screening pharmacist identifies a potential problem, it is left to that individual to determine if follow-up is required.

In response to this ongoing need, a resident-on-call service was developed, with an attempt to follow both the letter and the spirit of Canadian Hospital Pharmacy Residency Board requirements, which indicate that "the educational benefits to the resident take precedence over other services the organization may obtain from the resident". ${ }^{2}$ On the basis of past experience, we wanted to offer a necessary service that would give the residents a bona fide educational opportunity. Specifically, we wished to avoid tasks that were principally focused on distribution, such as determining if patients had brought in their own drugs and had proper documentation to acquire a new drug.

In an attempt to ensure that these "consults" would be of value to both the resident and the patient, 4 criteria were established:

- The issue to be dealt with by the resident on call had to have some learning value for the resident.

- The consult would take place after a delay of up to $24 \mathrm{~h}$. This delay also helped to ensure that the issue was of clinical importance.

- All potential consults would be forwarded to a coordinator to be reviewed for suitability. If the request was deemed suitable, the coordinator would contact the resident on call for that week.

- The service would be offered from Monday to Friday between 0800 and 1600 .

The 4 residents coordinated their schedules so that 1 resident was always on call starting in November 2008. For each consult, the pharmacist who screened the original order identified a potential clinical issue and forwarded this information to the coordinator, who contacted the resident on call if appropriate. The resident reviewed the patient's chart and met with the patient; on occasion, she also contacted family members, the community pharmacist, the family physician, consultants, and other health care providers, as appropriate. After the case had been worked up, it was presented to the coordinator, along with the resident's recommendations. After discussions with the coordinator, the resident's recommendations were documented in the chart.

From November 15, 2008, to April 30, 2009, a total of 9 consults were provided. The average approximate time to complete these consults was $2.5 \mathrm{~h}$ (range $25 \mathrm{~min}$ to $5 \mathrm{~h}$ ).

An informal anonymous survey was performed to determine the residents' perspective of the experience. All 4 residents agreed that the resident-on-call service was a valuable learning experience, and 3 of the 4 felt that they had contributed to favourable outcomes for patients. One resident found that it was difficult to organize her time while performing the resident-on-call activities. Each case was reviewed by the coordinator after the residents had worked it up, and all residents felt confident in their recommendations; however, only 1 of the 4 felt confident about the recommendations before reviewing the case with the coordinator.

Additional comments included "a very unique experience that I would not have normally had" and "the epitome of the resident experience". Ongoing concerns were the time required, especially if the resident was unfamiliar with the issue identified, and overall time management in relation to other responsibilities.

The residents were only infrequently called upon to provide on-call services, and the feedback, especially in terms of time constraints, would obviously be affected by the number of consults.

The coordinator deemed several requests for a residenton-call consult inappropriate, usually because they required immediate attention (e.g., sorting out allergies before dispensing medications) or because they had to do with the provision of a nonformulary drug. The relatively small number of issues for which consults were completed was probably related, at least in part, to the difficulty experienced by the pharmacists who originally screened the orders in identifying a specific reason for the resident-on-call consult.

In conclusion, the resident-on-call service provided residents with a valuable experience that was felt to contribute to patient care in a population of patients that is currently underserviced. Using this template, an opportunity exists for elaboration of both service and education.

\section{References}

1. Yoshida E. Workload and cost-benefit of hospital pharmacy residents. Can J Hosp Pharm 1993;46:147-154.

2. Canadian Hospital Pharmacy Residency Board. Accreditation standards. Ottawa (ON): Canadian Society of Hospital Pharmacy; 2009. Available from: http://www.cshp.ca/programs/residencyTraining/CHPRB info_e.asp.

Charles D Bayliff, PharmD

Residency Coordinator

Katherine Bateman, BScPhm

Irina Rajakumar, BScPhm

Nicole Parker, BScPhm

Shalene Wong, BScPhm

Hospital Pharmacy Residents (former)

Department of Pharmacy

London Health Sciences Centre

London, Ontario

Katherine Bateman is now with the Hamilton Health Sciences Centre. Irina Rajakumar and Nicole Parker are now with the London Health Sciences Centre. Shalene Wong is now with St Michael's Hospital, Toronto. 